\title{
Análise da comunicação acerca da sexualidade, estabelecida pelas enfermeiras, com pacientes no contexto assistencial do câncer de mama *
}

\author{
Lilian Cláudia Ulian Junqueira ${ }^{1}$ \\ Elisabeth Meloni Vieira ${ }^{2}$ \\ Alain Giami ${ }^{3}$ \\ Manoel Antônio dos Santos ${ }^{4}$
}

JUNQUEIRA, L.C.U. et al. Analysis on nurses' communication relating to sexuality to patients in the context of breast cancer care. Interface - Comunic., Saude, Educ., v.17, n.44, p.89-101, jan./mar. 2013.

This study investigated how nurses develop communication with mastectomized patients in relation to sexuality. This was a qualitative, descriptive-exploratory study. Twenty-eight nurses participated and in-depth interviews were used. The material was subjected to thematic content analysis. There were variations in the nurses' discourse, which were articulated in four categories: nurses do not communicate regarding sexuality issues; they communicate using evasive discourse and denial of sexuality within healthcare; they use fragmented communication that is typical of the biomedical model; and they use receptive integrated communication with family members and the healthcare team.

Nurses' difficulties in addressing sexuality issues within healthcare production were demonstrated. It is hoped that this study may arouse interest in further knowledge regarding the interface between sexuality and care within nursing education, thus favoring information and capacitation for other professionals in the team.

Keywords: Breast neoplasms. Sexuality. Communication and nursing.
Investigou-se como se desenvolve a comunicação acerca da sexualidade, estabelecida pelas enfermeiras, com as pacientes mastectomizadas. Trata-se de estudo qualitativo, do tipo descritivo-exploratório. Participaram 28 enfermeiras e foram utilizadas entrevistas em profundidade. $\mathrm{O}$ material foi submetido à análise de conteúdo temática. Houve variações nos discursos das enfermeiras, articuladas em quatro categorias: a enfermeira não comunica questões de sexualidade; comunica com discurso evasivo e com negação da sexualidade no cuidado; utiliza da comunicação fragmentada, própria do modelo biomédico; e se vale da comunicação acolhedora, integrada, junto a familiares e à equipe de saúde. Evidenciaram-se dificuldades das enfermeiras em contemplarem questões da sexualidade na produção dos cuidados em saúde. Espera-se que este estudo possa suscitar o interesse por novos conhecimentos acerca da interface da sexualidade e dos cuidados na formação em enfermagem, favorecendo a informação e capacitação de outros profissionais da equipe.

Palavras-chave: Neoplasias da mama. Sexualidade. Comunicação e enfermagem.
"Derivado de projeto de pesquisa financiado pela Capes (bolsa de Doutorado) e Fapesp (proc. 2009/50319-8).

${ }^{1}$ Doutoranda, Programa de Pós-graduação em Psicologia, Faculdade de Filosofia, Ciências e Letras de Ribeirão Preto, Universidade de São Paulo (USP). Bolsista de doutorado Capes. Avenida Bandeirantes, 3900, Monte Alegre. Ribeirão Preto, SP, Brasil. 14.040-901. lilianjunqueira@usp.br 2 Departamento de Medicina Social, Faculdade de Medicina de Ribeirão Preto, USP.

${ }^{3}$ Centre de Recherche en Épidémiologie et Santé des Populations CESP-U1018, Institut de la Santé et de la Recherche Médicale INSERM, Paris.

${ }^{4}$ Departamento de Psicologia, Faculdade de Filosofia, Ciências e Letras de Ribeirão Preto, USP. Bolsista de produtividade em pesquisa $1 \mathrm{C}$ do CNPq. 
ANÁLISE DA COMUNICAÇÃO ACERCA DA SEXUALIDADE ...

\section{Introdução}

A descoberta do câncer de mama suscita, na mulher, reações emocionais intensas, que podem desencadear angústias perante a possibilidade de morte e antecipação de múltiplas perdas, associadas à imagem corporal, ao sentimento de feminilidade e ao relacionamento afetivo-sexual (Silva, Santos, 2010, 2008; Fontes, Alvim, 2008; Rossi, Santos, 2003; Penson et al., 2000).

Santos et al. (2008) investigaram as influências desencadeadas pelo câncer de mama e seus tratamentos na vida afetiva e sexual de oito mulheres, por meio do método de estudo de caso. Concluíram que a maioria das mulheres percebe que houve diminuição na frequência das relações sexuais, sem comprometimento do relacionamento com o companheiro, havendo casos em que o parceiro se tornou mais atencioso. Inapetência sexual, dor durante as relações sexuais e dificuldades para excitar-se e alcançar o orgasmo foram as principais disfunções relatadas, decorrentes da doença e dos tratamentos.

Diante desses achados, pode-se questionar se a temática da sexualidade está sendo contemplada no cenário dos cuidados em saúde, voltados tanto para mulheres como homens. Estudo etnográfico de Pinheiro, Couto e Silva (2011), acerca da abordagem da sexualidade masculina em dois serviços de atenção primária à saúde, buscou compreender como a sexualidade dos homens se apresenta no contexto da assistência e como as demandas são abordadas pelos profissionais de saúde. Foram entrevistados 57 homens, que relataram como principais problemas: as infecções sexualmente transmissíveis, a prevenção do câncer de próstata e os problemas relativos à ereção. Em todos os participantes, observou-se que a abordagem profissional utilizada foi superficial, abreviada e ancorada na medicalização. Embora os usuários acatassem os parâmetros biomédicos, muitos apresentaram sinais de resistência, mostrando como as construções de gênero podem demarcar barreiras na assistência à saúde, como também podem, por outro lado, promover a construção de relações dialógicas entre profissionais e usuários da rede de saúde.

Dentre os profissionais de saúde, os membros da equipe de enfermagem são os que mais se fazem presentes no cuidado direto do paciente. Essa proximidade pode favorecer o conhecimento e a escuta sobre o sofrimento da mulher acometida pelo câncer de mama, incluindo seus temores e inquietações em relação ao impacto da doença e do tratamento sobre a sexualidade. Há farta literatura disponível a respeito das repercussões do câncer de mama sobre a sexualidade da mulher, contudo, diversos estudos alertam para a necessidade da melhoria da comunicação que os profissionais de saúde, em particular as enfermeiras, necessitam estabelecer em relação a essa questão nos cuidados à paciente (Lindau et al., 2011; Teixeira et al., 2009; Fontes, Alvim, 2008; Hordern, Street, 2007).

Perante as várias facetas dos cuidados de enfermagem, é imperativo circunscrever a comunicação e sua aplicação no processo de cuidado à dimensão da sexualidade do paciente oncológico. A comunicação é uma das ferramentas que propiciam a personalização da assistência em saúde, de acordo com as necessidades do paciente, oferecendo um cuidado competente e humanitário. O enfermeiro vale-se de sua competência em comunicação para estabelecer relacionamento com as pessoas com as quais interage nas várias equipes existentes nas instituições de saúde, assim como com os pacientes e suas famílias (Stefanelli, Carvalho, Arantes, 2005).

Partindo do cenário contemporâneo de inovações constantes e transformações radicais nas relações afetivas, Giddens (1993) tratou da sexualidade inserida no contexto das relações humanas pela ótica da transformação da intimidade. Para este autor, as relações humanas são construídas e reorganizadas ao longo da história. A mudança na construção da intimidade é explicada pela transformação do "amor romântico" no "amor puro", na medida em que o feminino é desvinculado dos aspectos complementares da reprodução e da maternidade. Atualmente, o exercício da sexualidade propicia o desenvolvimento de estilos de vida bastante variados. A sexualidade deixa de ser uma condição natural e reprodutiva, mas atua, na contemporaneidade, como uma dimensão constitutiva da identidade, sendo um ponto de conexão entre o corpo, a autoidentidade e as normas sociais, que vão influenciar e definir as condutas em sociedade.

De forma análoga, o conceito de saúde sexual passa por transformações histórico-culturais, influenciando normas e condutas humanas. O processo de modernização da sexualidade estimulou o 
otimismo sexual e atravessou toda a metade do século XX buscando uma legitimidade junto ao campo da saúde, circunscrevendo-se à área médica. Nesse enfoque, a saúde sexual é definida pela busca de bem-estar sexual por meio da medicalização e qualidade de vida (Giami, 2007). Desse modo, a sexualidade passa a ser relacionada não somente aos aspectos reprodutivos, mas, também, à obtenção de prazer, à vontade de viver sentimentos de intimidade e à expressão de sentimentos que definem a identidade pessoal. Nesse sentido, a sexualidade sofre influência de aspectos biológicos, culturais e sociais. Assim, a compreensão das condutas sexuais varia dependendo da época, da cultura e do contexto em que a pessoa vive (Macieira, Maluf, 2008).

Barthon-Burke e Gustason (2007) abordam a sexualidade como uma integração das dimensões física, psicológica e social dos indivíduos, que envolve mais do que o ato sexual com finalidade reprodutiva, uma vez que engloba: aspectos do ser homem ou ser mulher, do como nos tornamos o que somos, como pensamos sobre esse modo de ser, como nos relacionamos uns com os outros e lidamos com as consequências das interações que estabelecemos.

No que diz respeito ao relacionamento entre paciente e profissional de saúde, nas dimensões que envolvem a sexualidade e a intimidade, Hordern e Street (2007) realizaram estudo qualitativo focalizando a perspectiva de pacientes com câncer de mama e de profissionais da equipe de saúde que Ihes prestam assistência. Encontraram divergências no tocante à abordagem e comunicação da sexualidade durante a consulta médica. Os pacientes relataram temas como: sobreviver é mais importante do que viver a sexualidade; há necessidade de ter confiança no profissional; os pacientes procuram opções de tratamento com os médicos, mas não recorrem ao profissional para esclarecer dúvidas acerca da sexualidade; ao buscarem esse esclarecimento, preferem se abrir com os amigos íntimos ou pessoas próximas.

Ao se examinar o panorama atual do cuidado, nota-se que o paradigma de assistência à saúde baseado no modelo biomédico ainda é prevalente na sociedade contemporânea. Esse paradigma entende o indivíduo como um corpo biológico, constituído por órgãos e sistemas, em uma concepção mecanicista e funcional, segundo a qual a doença é compreendida como uma disfunção a ser corrigida. A função do profissional de saúde seria a de corrigir, restaurar, reparar as peças avariadas da máquina biológica (Capra, 1982). Nesse modelo de assistência, a prática está centrada na utilização da tecnologia, na intervenção técnica e na comunicação dos procedimentos, bem como em prescrição de estilos de vida tidos como saudáveis e padrões de comportamento esperados. Assim, a visão da saúde está totalmente subsumida à questão da doença que precisa ser medicalizada.

Nos últimos tempos, vem sendo desenvolvido um novo paradigma de saúde baseado no modelo biopsicossocial, que proporciona uma visão integral do ser e do adoecer, que compreende as dimensões física, psíquica e social. Esse paradigma preconiza que a formação do profissional de saúde deve ir além das habilidades técnico-instrumentais, e que é preciso evoluir no sentido de se assegurar o desenvolvimento das capacidades relacionais, que permitem o estabelecimento do vínculo adequado e uma comunicação efetiva (De Marco, 2006).

Nessa direção, o objetivo do presente estudo foi investigar como se desenvolve a comunicação acerca da sexualidade, estabelecida pela enfermeira, no contexto do cuidado em saúde para as mulheres mastectomizadas. Analisar o modo como a enfermeira oferece sua escuta e presta cuidados à mulher com câncer de mama, especialmente acerca de sua sexualidade, pode suscitar novos conhecimentos acerca da interface da sexualidade e dos cuidados em oncologia. Desse modo, o presente estudo poderá contribuir para que se reflita sobre a formação das enfermeiras oncológicas e de outros profissionais da equipe multidisciplinar, fortalecendo a construção de estratégias de intervenção que possam contemplar o acolhimento da dimensão sexual na produção dos cuidados em saúde dispensados à mulher que se encontra em tratamento para o câncer de mama.

\section{Método}

Estudo descritivo-exploratório, desenvolvido na abordagem de pesquisa qualitativa. Participaram 28 enfermeiras, com idades variando entre 23 e sessenta anos, com um mínimo de dois anos e máximo de 
25 anos de experiência profissional no cenário dos serviços que prestam assistência a mulheres com câncer de mama. As participantes atuavam em diferentes instituições e contextos de assistência de um município do nordeste paulista. Essas instituições, de caráter público e privado, incluem serviços como: ambulatórios, enfermarias, centrais de quimioterapia, radioterapia e serviços de atendimento domiciliar.

Para o recrutamento das participantes, foi realizado um levantamento de todos os profissionais de enfermagem que assistiam diretamente mulheres acometidas pelo câncer de mama no município. Foram realizadas entrevistas em profundidade, em que a participante foi convidada a falar livremente sobre o tema, sendo que as perguntas da entrevistadora, quando necessárias, eram formuladas no sentido de dar mais relevo e profundidade às respostas obtidas.

A entrevista teve como questão disparadora: Como você coloca a sexualidade na sua prática profissional? Seguiu-se um roteiro inspirado no guia de escuta proposto por um dos pesquisadores (Giami, 2007), que realizou estudo similar com enfermeiras francesas. A ordem dos assuntos tratados não obedeceu a uma sequência rígida, mas foi determinada pelas relevâncias e ênfases atribuídas, pelas entrevistadas, ao assunto em pauta (Minayo, 2008).

Para a análise do material coletado, foram seguidos os passos metodológicos da análise de conteúdo temática, recomendados pela literatura (Minayo, 2008): (1) Pré-análise: compreende leituras flutuantes e exaustivas, seguidas da organização do material e da sistematização de ideias e eixos estruturantes, que constituirão o corpus de análise; (2) Exploração do material: esse passo compreende a categorização dos dados, utilizando expressões ou palavras significativas em unidades de registros, a partir da similaridade dos conteúdos; e (3) Tratamento dos dados obtidos e Interpretação: essa etapa corresponde à análise dos dados, com interpretação dos significados dos conteúdos temáticos com base no referencial teórico assumido pelo pesquisador, podendo também abrir caminhos para novas dimensões teóricas e interpretativas.

Foi assegurada, a todas as participantes, a possibilidade de ler, compreender a proposta da investigação e assinar o Termo de Consentimento Livre e Esclarecido, que garantia o direito à confidencialidade em relação aos dados fornecidos, em obediência à legislação que regulamenta a pesquisa que envolve seres humanos, de acordo com a Resolução n 196/96 do Conselho Nacional de Saúde (Brasil, 1996).

\section{Resultados e discussão}

As categorias foram construídas, analisadas e discutidas frente à variedade de respostas obtidas à questão norteadora, permitindo identificar quatro núcleos temáticos, que serão apresentados a seguir.

\section{A enfermeira não comunica questões de sexualidade no cuidado à paciente}

Essa categoria engloba os diferentes motivos apontados para a não-comunicação da sexualidade no cuidado prestado à paciente, que foram identificados nos relatos das enfermeiras, tais como: preocupações apenas com o tratamento e seus efeitos colaterais no corpo físico; a sexualidade não é uma prioridade na consulta de enfermagem, porque a preocupação é com a preservação da vida; o uso da estratégia de delegação do diálogo aos profissionais de outras especialidades; barreiras culturais e falta de tempo como justificativas para a não-comunicação do assunto.

\footnotetext{
"A mulher vai passar por tanta coisa, né? Câncer de mama já é um... Tira a mama dela, ela já fica deprimida, queda de cabelos... Elas ficam deprimidas. Então eu acho que, nesse momento, a sexualidade dela diminui com o marido. Eu acredito, com base no que eu vejo aqui... a quimioterapia, elas ficam, sabe, debilitadas. Elas não se sentem bem. Então eu acredito que, nesse momento, não é o momento em que elas... Elas pegam... Elas voltam mais a vida delas pro tratamento". (E11, 24 anos, solteira)
} 
As participantes ressaltam a importância de se priorizarem outros aspectos no cuidado à mulher mastectomizada, tais como: acolhimento no diagnóstico, apoiar o tratamento monitorando sinais e sintomas, informar sobre os efeitos colaterais das medicações. As enfermeiras orientam acerca das questões estéticas, incluindo cuidados com a pele, por meio do oferecimento de recomendações quanto ao uso de protetor solar e os cuidados que elas devem ter em relação à queda dos cabelos.

"A gente fala, assim, da pele, para passar o protetor, passar um creme hidratante. Porque está muito sol. Evitar o sol, né? Hidratar-se bastante, porque pode ter diarréia. E aí a gente vai orientando que o cabelo vai cair. Que nem homem que quiser raspar a cabeça, mulher também... Às vezes, a gente até fala pra raspar, porque vai cair bastante". (E16, 41 anos, casada)

As enfermeiras também pontuam, em seus relatos, a preocupação com a preservação da vida como valor supremo e com a debilitação física que a doença e o tratamento acarretam, além da temida possibilidade da morte, sempre onipresente no horizonte do câncer. Desse modo, privilegiam, em seus discursos, aspectos relacionados à evolução da doença e à busca da cura. Porém, nessa compreensão de que existem outras prioridades mais relevantes com as quais as pacientes devem se preocupar, que não as vivências em relação à sexualidade, as participantes recorrem à questão existencial que dilacera a mulher nesse momento de suas vidas, que é a de ter de lidar com a incerteza quanto a saber se vai sobreviver ou morrer. A questão da sexualidade da mulher ficaria em segundo plano, de maneira que não haveria necessidade de ser abordada pelas profissionais da enfermagem. Essa racionalização reflete a ênfase excessiva na cura, entendida como a total remoção das condições que deflagraram a doença e geraram o sofrimento. Não por acaso essa é uma das características proeminentes do modelo biomédico, que mira a remissão da doença, e não as necessidades da pessoa doente.

“[...] pra começar eu acho que elas... a última coisa que elas perguntam é isso. A maioria, pelo menos das que eu atendo, porque elas estão mais preocupadas em saber se vão morrer, se vão curar, se vão passar mal". (E9, 35 anos, casada)

Essa percepção contrasta com as preocupações observadas nas mulheres mastectomizadas. Estudo qualitativo, desenvolvido com cinquenta pacientes e 32 profissionais da saúde, mostrou que as mulheres consideram que a comunicação sobre sexualidade com o profissional pode ser negociada e que elas tentam conversar, porém os profissionais evitam abordar as questões sexuais durante a consulta. Já os profissionais de saúde de diferentes especialidades relataram que preferem evitar o assunto e que, quando o abordam, recorrem à estratégia do bom humor. Consideram que abordar essas questões pode representar um risco e, para algumas pacientes, não seria apropriado. Sentem-se constrangidos e vivenciam sentimentos de desconforto e incerteza ao abordarem a sexualidade, bem como dificuldades em relação à cultura e à linguagem do paciente. Desse modo, ao discutirem esse assunto no ambiente hospitalar, preferem focalizar no diagnóstico e na medicalização da sexualidade (Hordern, Street, 2007).

As enfermeiras que admitem que os temas relativos à sexualidade aparecem em sua comunicação com a paciente, mas que não os comunicam diretamente, costumam delegar essa tarefa aos profissionais de outras especialidades, que elas julgam mais capacitados ou melhor preparados para manejarem essas questões. Esse expediente acaba fragmentando a assistência. Assim, a enfermeira perde preciosas oportunidades de trabalhar essas questões, ao se esquivar da tarefa de lidar com esses temas na sua prática profissional. Por exemplo, na visão das enfermeiras, o psicólogo cuida dos aspectos subjetivos e psicológicos; a assistente social e a terapeuta ocupacional dão respaldo aos aspectos sociais e da reabilitação física, e o médico cuida dos aspectos clínicos e preventivos, assim como das implicações para o organismo da realização do ato sexual, o que reduz o conceito ampliado da sexualidade a uma única dimensão: o ato sexual.

As enfermeiras enfatizam, ainda, que não encontram, em sua prática profissional, condições específicas para promoverem a comunicação da sexualidade ou da saúde sexual, dado o seu despreparo pessoal e técnico para abordar a paciente, os familiares ou o casal, em assuntos dessa natureza. 
ANÁLISE DA COMUNICAÇÃO ACERCA DA SEXUALIDADE ...

Ausência de capacitação técnica, que sentem que deveria ter sido oportunizada ao longo da formação acadêmica; insuficiência de conhecimento adequado e parco domínio do assunto; falta de tempo, de espaços apropriados e de garantia de privacidade nos serviços de saúde, considerando que a sexualidade ainda é um tema cercado de tabus e que envolve a intimidade psíquica das pessoas; precariedade do vínculo estabelecido com a paciente, em decorrência da organização fragmentada do trabalho no contexto da saúde - essas são condições apontadas como de difícil manejo, na perspectiva das participantes.

“Aí eu ia falar para ela: 'mas, e aí, como foi sua reação?' Eu não ia falar assim... Eu, particularmente, gostaria de saber como é que eu vou lidar com esse momento, que eu me coloco no lugar dela... Eu estou ali, o parceiro vira e não quer transar, porque olhou e se assustou, como é que é isso? Eu acho que é um choque... O que eu vou fazer com isso?" (E1, 48 anos, casada)

As enfermeiras relataram ainda encontrar outras barreiras em relação à comunicação da sexualidade, como as questões de gênero e a idade da paciente, que promovem o distanciamento do profissional em relação ao assunto, inibindo a possibilidade de abordar a temática mesmo quando atua em equipe multiprofissional.

As enfermeiras relataram que sentem vergonha e desconforto pessoal, sentimentos que as impedem de abordar o assunto junto às pacientes. Mencionaram, como barreiras culturais: o baixo nível educacional das pacientes, que exige o uso de linguagem simples; a idade, e as diferenças étnicas, que as fazem manter reservas em relação à comunicação da sexualidade no âmbito social (Pinheiro, Couto, Silva, 2011). Por exemplo, uma das participantes se referiu ao seu ambiente cultural de origem oriental para revelar suas dificuldades de expressão de assuntos relativos à sexualidade. Dessa maneira, é compreensível que priorizem: a manutenção da rotina de cuidados concretos com o corpo, orientações quanto aos efeitos colaterais dos tratamentos, preocupação com o manejo dos sintomas de dor e desconfortos físicos.

Muitas vezes, o volume de trabalho e a falta de tempo agem como barreiras para a exploração reflexiva dos problemas relacionados à sexualidade e à saúde sexual. Sem a incorporação, pelos profissionais, da ideia de que a discussão dessa dimensão faz parte do seu trabalho, os pacientes podem sentir que algumas de suas necessidades são negligenciadas ou deixadas de lado pelos profissionais (Dizon et al., 2008). De acordo com Giami (2007), as últimas definições de saúde sexual propostas pela Organização Mundial da Saúde, em 2000, confrontam os profissionais de saúde com a questão dos direitos sexuais e do comportamento sexual responsável, e apresentam a saúde como um valor do mundo contemporâneo, assegurando, assim, uma coerência de valores e princípios morais que devem nortear as ações em saúde.

\section{A enfermeira comunica com discurso evasivo, de negação da sexualidade no cuidado}

Na perspectiva das enfermeiras, as pacientes não relatam nem questionam sobre sexualidade por não desejarem (ou por sentirem vergonha de) abordar essas questões. As profissionais, por sua vez, alegam que também não abordam o tema, pois nunca são questionadas em relação a esse aspecto pelas pacientes e, também, não conversam sobre essa temática com os demais membros da equipe de saúde, por se sentirem constrangidas. Assim, apresentam um discurso evasivo quando questionadas acerca do tema, adotando posturas profissionais marcadas por hesitações e atitudes reservadas, sustentando um discurso reticente, entrecortado por pausas, em que o que se sobressai não é tanto o que se fala, mas a dimensão do que é silenciado. Os silêncios, muitas vezes, são seguidos de risos desencadeados por ansiedade.

Assim, as enfermeiras recorrem a mudanças repentinas de assunto durante a conversa, fabulações que preenchem lacunas e tentativas de evasão no discurso. Esses momentos são alternados com outros, nos quais tangenciam o assunto e, por vezes, apresentam um relato esvaziado de significado. Esses 
artifícios costumam vir acompanhados de um mecanismo de defesa recorrente, que é a negação desse tipo de demanda das pacientes. Negação que, por vezes, aparece associada a relatos contraditórios que denotam a concepção de cuidado que embasa as práticas de saúde.

“Olha, os nossos pacientes aqui, eles não costumam relatar muito não esta... eles são, principalmente, as mulheres... agora muito difícil isso, questionarem a gente ou colocarem... A gente também não questiona muito não, não entra em detalhes com eles. Fica meio que assim... Um ou outro que comenta, que fala que se sente mutilado, mas assim, é muito difícil. Olha, sinceramente, comigo ninguém chegou e me abordou assim". (E3, 28 anos, solteira)

A sexualidade ainda não está legitimada como dimensão a ser considerada no cuidado pelo profissional de saúde. Para que se possa reverter essa situação, o profissional necessita reconhecer os pacientes como seres sexuais, dotados de necessidades e desejos singulares. Só assim poderão oferecer, às mulheres acometidas pelo câncer de mama, suporte, aconselhamento e orientações quanto ao manejo dos aspectos relativos ao corpo e à sexualidade, rompendo o silêncio que ronda essa importante dimensão da vida humana (Higgins, Barker, Begley, 2006).

Os profissionais de saúde, mesmo aqueles que adotam uma filosofia de cuidado baseada em uma abordagem biopsicossocial, mostram-se reticentes em discutir questões sobre sexualidade com seus pacientes, possivelmente devido ao tabu que envolve o tema, mas, também, por questões pessoais relacionadas ao sexo e à sexualidade e pela carência de preparo, conhecimento e habilidades necessárias a essa abordagem (Rice, 2000).

“[...] já numa esfera mais privada ou uma consulta psicológica mesmo entre ela e o paciente, mas pra enfermagem isso ainda é um tabu. A sexualidade do paciente ainda é um tabu". (E12, solteira, 36 anos)

Percebe-se que tratar de questões da sexualidade desperta, nas enfermeiras, sentimentos de constrangimento. Essa reação pode estar relacionada à apropriação que cada uma faz do tema em sua própria história de vida. Ao longo do processo de desenvolvimento psicoafetivo, podem ter incorporado a sexualidade como algo negativo, graças a uma experiência marcada pela falta de exploração franca e aberta do tema no cotidiano (Ressel, Gualda, 2004). Isso decorre também da construção social da sexualidade na tradição judaico-cristã. Nesse sentido, é importante destacar que a exposição da sexualidade causa constrangimento, pois é tema identificado ao universo privado. Acrescente-se a isso o fator agravante de que, na perspectiva das enfermeiras, há um entendimento generalizado de que tratar desse tema não é de sua competência profissional. Assim, a abordagem da sexualidade conflituaria com o modelo biomédico hegemônico que regula o funcionamento das profissões da saúde.

\section{A enfermeira utiliza comunicação fragmentada própria do modelo biomédico}

Essa categoria de análise congrega o modo parcial de comunicação, no qual o profissional de enfermagem apresenta o tema ao paciente priorizando aspectos clínicos e cuidados protocolares, com a clara divisão social do trabalho entre os diferentes saberes técnicos que compõem a equipe de saúde. Há segmentação das fontes de informação, configurando uma modalidade fragmentada de comunicação (Capra, 1982), com a priorização dos aspectos clínicos. A comunicação se dá pela oferta de informações que envolvem o ato sexual, atreladas a uma preocupação com o bom funcionamento dos órgãos.

Assim, os saberes sobre a sexualidade são reconhecidos como pertencentes ao âmbito de atuação das enfermeiras, mas no nível das orientações sobre aspectos preventivos, englobando: o uso de preservativos e lubrificantes, os riscos envolvidos na promiscuidade, a necessidade de controle do número de parceiros e a prevenção de doenças sexualmente transmissíveis. Adicionalmente, são oferecidas orientações relativas aos efeitos do tratamento sobre a prática da relação sexual, devido ao 
ressecamento da mucosa vaginal, à perda ou diminuição da libido e às questões estéticas associadas ao desfiguramento corporal e à reconstrução mamária.

Nessa modalidade de comunicação, o cuidado é suprido pela aplicação de uma medida protocolar, seguindo um guia de instruções previamente elaborado no serviço, um manual de recomendações práticas ou, mesmo, uma lista de orientações gerais. A comunicação estratificada pode ser expressa também nos relatos nos quais o profissional de enfermagem parece estar disposto a prover assistência, porém oferece apoio caracterizado por opiniões pessoais, utilizando de um discurso de senso comum ou que minimiza o sofrimento sem, de fato, oferecer uma possibilidade de elaboração dos conteúdos emocionais mobilizados pela experiência do câncer de mama.

"Então, a gente fala: "ó, é vida normal. Vocês vão seguir em frente, tocar a vida de vocês normal... Se conseguirem, vão trabalhar, vão se alimentar normal". É óbvio que tem as reações, tem, tem a fraqueza, tem o mal-estar, a queda do estado geral, às vezes a alimentação não vai ser legal, a gente orienta os tipos de alimentação, a libido pode aumentar, pode diminuir, pode manter o nível". (E3, 28 anos, solteira)

Algumas profissionais relataram que só se dispõem a comunicar sobre sexualidade frente à demanda da paciente, quando esta oferece abertura para tratar do assunto. As enfermeiras consideram que esse é um assunto íntimo e de difícil abordagem, e referem a necessidade de se dispor de um local adequado para abordá-lo. Mostraram-se temerosas de serem invasivas ao abordarem a paciente.

“[...] eu sempre espero. Primeiro, que a pessoa me traga... porque, assim... algumas pessoas - aí é o meu receio - eu penso, às vezes, estar sendo... invadindo, sabe? Ou sendo muito invasiva. Então, eu sempre espero a brecha... É claro que eu, enquanto profissional, eu sempre tenho que ter essa preocupação, né?". (E27, 25 anos, solteira)

Em alguns trechos dos relatos, a dificuldade em abordar o tema da sexualidade, por parte das profissionais, é minimizada com a utilização de outros canais de comunicação, como estratégias de enfrentamento em relação ao embaraço que o assunto produz. Como se a utilização de outros recursos - tais como instrumentos, protocolos, manuais de orientações gerais que incluem a questão da sexualidade, livro institucional, e-mail e oficinas de grupo - pudesse substituir ou atender de maneira satisfatória a demanda da mulher, evitando o árduo, porém indispensável exercício da comunicação direta.

"[...] nós temos um protocolo... todo paciente de câncer de primeira vez passa conosco com a enfermeira... com o serviço social e com a psicologia, né?". (E26, 47 anos, casada)

\section{A enfermeira utiliza a comunicação acolhedora e integrada junto aos familiares e à equipe de saúde}

Essa categoria abrange os relatos das profissionais que indicam que elas se esforçam para desenvolver um diálogo acolhedor em relação à necessidade de comunicação da sexualidade das pacientes com câncer de mama; assim como buscam atender as demandas dos familiares e dos colegas de equipe. Esse movimento consiste em acolher a demanda e entrar em sintonia com a necessidade identificada e, somente a partir dessa experiência, dispor-se a elaborar uma estratégia de cuidado individualizado.

Foram encontradas poucas profissionais que assumem para si a responsabilidade de manejar o tema da sexualidade na assistência oferecida; que se mostram dispostas a fazer uma leitura da comunicação não verbal; que priorizam o que as mulheres têm a dizer ao invés de se sentirem obrigadas a emitir automaticamente um cuidado pronto; que demonstram empatia com as necessidades de abordar a sexualidade ou se mostram confortáveis diante da responsabilidade perante seu papel de orientadoras nesse âmbito do cuidado. 
“[...] a gente primeiro procura ouvir muito as pacientes. Elas têm uma certa dificuldade de expor, quando uma coloca as outras se encorajam... aí, então, a gente procura ouvir mais... E procura mais ir coordenando a fala; as falas e os pensamentos, do que estar colocando aquilo que a gente pensa a respeito. A gente quer saber como é que elas se sentem a respeito". (E15, 60 anos, divorciada)

Com relação à comunicação de sexualidade junto às pacientes, as enfermeiras relatam que acolhem a demanda e percebem a manifestação de sentimentos, o humor e afeto presentes nos discursos das mulheres, assim como valorizam a observação dos comportamentos não verbais, como o fato de cobrirem o corpo durante a consulta. Percebem a pessoa como uma totalidade a ser cuidada de forma holística e íntima, e não consideram que tratam somente da doença, desde a etapa do diagnóstico até o desfecho do tratamento. Preocupam-se com a exposição dos corpos no cuidado prestado.

"[...] ou até o jeito delas se cobrirem, se você vê que elas sentem incomodadas com a mama ou fazem algum comentário a respeito do marido. Comentário... comentário no geral... da vida... com as pacientes. Aí dá para você perceber se ela está tendo algum problema, ou não". (E22, 31 anos, casada)

Esse diálogo com a paciente pode ser facilitado quando as profissionais tiveram oportunidade de adquirir conhecimentos mediante cursos e especializações que realizaram, ou mesmo no próprio serviço, o que as leva a assumirem uma atitude proativa. Também percebem consequências subjetivas do adoecer que necessitam ser cuidadas, como os prejuízos na autoestima e nos aspectos estéticos, o que contribui para refinar a sensibilidade para abordar a sexualidade. Buscam conhecer a paciente e suas necessidades de forma individualizada, esclarecem suas dúvidas, preocupam-se com o modo adequado de abordar a mulher na intimidade.

“[...] 'Aí como que vai ser quando eu colocar tal roupa? Como que vai ficar, né?' E, apesar de ser aquela coisa muito recente que eu vivi, assim, né. Então, acabou de fazer a cirurgia... os dois, três, quatro, cinco primeiros dias... primeira semana, mas ela já se questionava e não só com isso... Questionava também assim... Não só a perda da mama ou de alguma parte, até a perda do cabelo, da imagem, perda da feminilidade, eu acho que era mesmo, né. 'Como que vai ficar quando eu colocar tal roupa?' Ou: 'Ai... eu vou perder o meu cabelo. E aí?'". (E23, 23 anos, solteira)

Especificamente em relação à sexualidade, para haver uma comunicação acolhedora e proativa do tema, faz-se necessária a legitimação dessa dimensão da vida como um aspecto a ser cuidado pela enfermagem. Muitas vezes, ouvir e responder às demandas, explorar os sentimentos e oferecer informações são medidas suficientes para a maioria das mulheres assistidas se sentirem acolhidas em suas necessidades. Apenas uma pequena parte das pacientes necessitará de atendimento especializado e irá requerer um encaminhamento específico (Higgins, Barker, Begley, 2006).

A categoria 4 congregou depoimentos que sugerem que as enfermeiras reconhecem, na paciente $e$ em seus familiares, atores sociais coparticipativos no tratamento. Uma das consequências desse posicionamento é que as decisões são resultantes de reflexões conjuntas e não impostas pelo poder autocrático da autoridade de saúde. Esse posicionamento empodera a paciente, levando-a a assumir corresponsabilidade por seu tratamento e, portanto, por sua recuperação. Fazer do paciente um sujeito reflexivo de suas ações e decisões pode contribuir para aumentar a participação ativa no tratamento. Santos et al. (2008) chamam a atenção para a necessidade de criação de espaços em que o paciente possa articular um discurso que expresse a singularidade de seu desejo. Para tanto, faz-se necessária uma escuta diferenciada pelo profissional, acolhendo a queixa das pacientes em sua particularidade, e não apenas buscar uma normatização da função sexual a qualquer custo.

Por fim, é válido ressaltar a importância do papel do parceiro afetivo-sexual como suporte social na reabilitação da mulher mastectomizada. Biffi e Mamede (2004) identificaram que o apoio social 
ANÁLISE DA COMUNICAÇÃO ACERCA DA SEXUALIDADE ...

oferecido pelos parceiros sexuais significou a demonstração de afeto na compreensão da situação vivenciada por suas esposas, mesmo que de forma silenciosa, por meio de incentivos às estratégias de autocuidado e colaborando na realização das atividades domésticas. Os parceiros percebem-se úteis ao oferecerem atenção no manuseio do dreno, na realização dos curativos, no estímulo à realização de exercícios físicos e na manifestação de preocupação com a nova imagem corporal de suas parceiras. No entanto, na esfera da sexualidade apresentam dificuldades em apoiar a parceira e em estabelecer comunicação aberta em relação ao tema, somadas aos sentimentos de impotência e insegurança que vivenciam ao terem de lidar com o diagnóstico de câncer e com a necessidade de reorganizar as atividades do lar.

Hautamaki et al. (2007) recomendam que a discussão deve ser iniciada pelos profissionais da equipe de saúde, deixando os pacientes e familiares com a opção de continuarem ou não com a discussão. Afirmam ser particularmente importante fornecer, aos profissionais, qualificação e instruções adequadas em relação a como abrir as discussões em áreas delicadas como a sexualidade. Esse treinamento também é muito importante para que os profissionais possam rever sua própria sexualidade, o que pode facilitar que tratem o assunto com os pacientes de forma natural e apropriada, evitando preconceitos e barreiras na comunicação.

\section{Considerações finais}

O presente estudo proporcionou o desvelamento das variadas modalidades de comunicação no cotidiano do cuidado às pacientes mastectomizadas, desde não comunicar questões de sexualidade, passando pelo processo de uma comunicação utilizando um discurso evasivo e negação da sexualidade no cuidado, por vezes apresentando, ainda, a comunicação fragmentada, própria do modelo biomédico, até se aproximarem da comunicação acolhedora, integrada, junto a familiares e à equipe de saúde. Essa diversidade reflete o modo como as enfermeiras lidam com a questão da sexualidade em sua prática assistencial.

Os achados evidenciaram a dificuldade com que o tema é tratado na prática profissional, seja na forma de comunicar ou nas relações interpessoais estabelecidas com as pacientes e familiares. Foram identificadas posturas evasivas de esquiva, negação, hesitação, silêncios e desvios de assunto quando confrontadas com as demandas das pacientes no campo da sexualidade. As enfermeiras buscam justificar as dificuldades que vivenciam para a implementação de uma comunicação mais aberta e efetiva em sexualidade pela via do excesso de atribuições e sobrecarga de trabalho. Essas racionalizações giram em torno do volume intenso de atividades protocolares, do tempo exíguo de que dispõem para cumprir com seus afazeres profissionais, das questões de gênero relacionadas à sexualidade feminina e das barreiras pessoais e culturais existentes para abordar livremente a temática junto às pacientes.

As enfermeiras participantes deste estudo, em sua maioria, apontaram para a necessidade de aperfeiçoamento próprio, assim como dos demais membros da equipe de saúde, visando a facilitar o manejo da sexualidade durante o cuidado. Esse aperfeiçoamento de competências específicas seria proporcionado mediante a implementação de reuniões para discussão de casos e decisões conjuntas, ou por meio do encorajamento de um diálogo mais franco e aberto dentro da própria equipe de enfermagem. Nesse caso, haveria um respeito maior às diferenças, que lhes permitiriam assumir posições perante a diversidade de situações enfrentadas em seu cotidiano. Nessa direção, as profissionais de enfermagem compreendem que a incorporação de outras facetas da pessoa, afora a dimensão biológica, potencializaria os resultados do trabalho da equipe.

A formação da enfermeira acompanha os preceitos biomédicos, com o acréscimo de ser uma profissão claramente referenciada ao gênero feminino em sua origem, estando permeada pela incorporação de um ideal de sexualidade asséptica e silenciada. Essa "assexualidade" impõe limites e regula a relação entre cuidador e sujeito cuidado (Ressel, Gualda, 2004). Para que a sexualidade seja cuidada com qualidade e sensibilidade, a enfermeira necessita ter um embasamento sobre o processo 
de desenvolvimento da sexualidade nas diferentes etapas do ciclo vital, assim como necessita conhecer o impacto das consequências advindas do processo do adoecer.

Para compreensão das dificuldades pessoais, barreiras e distanciamentos da temática da sexualidade, é preciso retroceder à evolução da sexualidade ao longo da história da humanidade, para melhor entendimento da época contemporânea. O tema, que foi em grande parte desmistificado e desvinculado de concepções morais nos últimos cinquenta anos, adquire ampla visibilidade no momento atual. Segundo Giddens (1993), essa visibilidade está relacionada à transformação social da intimidade e dos laços afetivos entre as pessoas, bem como às redescrições contemporâneas do amor e do erotismo, e às suas articulações com dimensões como poder e gênero.

Animar discussões sobre questões relacionadas à saúde sexual, com mulheres que vivenciam o câncer de mama e seus parceiros, é uma capacidade e, também, uma competência a serem desenvolvidas ao longo do tempo. Os achados do presente estudo sugerem que muitas enfermeiras que trabalham em oncologia encontram dificuldades em abordar o tema e tendem a evitar o assunto no cuidado dispensado à mulher mastectomizada, deixando as pacientes com muitas questões sem respostas. Nessa perspectiva, a enfermeira precisa se perceber mais na relação, sendo permeável a ouvir os próprios conceitos e preconceitos arraigados ao longo de sua vida. É preciso compreender quais são os conceitos de sexualidade, de relacionamento e de vínculo amoroso que essas profissionais compartilham e que sustentam suas práticas, ou seja, que crenças, valores e sentimentos constituem suas convicções íntimas. Só assim será possível ampliar seu autoconhecimento, com o objetivo de articulá-lo ao conhecimento resultante da experiência profissional, com o intuito de alargar as possibilidades de cuidado à sexualidade.

Outro aspecto relevante que emergiu nas falas foi a falta de confiança pessoal e de capacitação profissional para abordar a temática, entendida como um tabu social de difícil comunicação na área da saúde, seja com as pacientes ou com algum outro membro da equipe. Por esse motivo, essa tarefa é delegada a outro profissional da equipe de saúde, rotulado como mais capacitado, e que pode ser o médico ou o psicólogo. Esse aspecto, que sugere a fragmentação do cuidado, reflete o modo como a sexualidade é considerada pelos profissionais da saúde, seja ela na perspectiva da medicina e da medicalização, ou do ponto de vista da psicologia e dos transtornos mentais, convergindo para um modo de cuidar com forte ênfase em classificações patologizantes e reducionistas.

Acredita-se que o presente estudo traz avanços importantes no conhecimento dos diferentes modos de comunicação que se estabelecem no cotidiano das enfermeiras oncológicas, fornecendo subsídios para o planejamento do cuidado em enfermagem à mulher acometida por câncer de mama. Em particular, traz elementos para refletir sobre a necessidade de o profissional estabelecer uma comunicação que consiga identificar recursos potencializadores de qualidade de vida, ao mesmo tempo em que valoriza os aspectos culturais, os modos de existência que se revelam frente aos fatos adversos que ocorrem durante o tratamento do câncer de mama e que são cotidianamente ativados pelos atores socioculturais coexistentes. O cuidado em enfermagem deve incluir o acolhimento de todos os elementos que apresentem relação com a vivência da mulher, inclusive em relação à sua sexualidade.

\section{Colaboradores}

Os autores trabalharam conjuntamente em todas as etapas de produção do manuscrito. 


\section{Agradecimentos}

Agradecemos o apoio recebido da Coordenação de Aperfeiçoamento de Pessoal de Nível Superior - CAPES, da Fundação de Amparo à Pesquisa do Estado de São Paulo (FAPESP) e do Conselho Nacional de Desenvolvimento Científico e Tecnológico (CNPq), que proporcionaram o fomento para o projeto de pesquisa que gerou o presente artigo.

\section{Referências}

BARTHON-BURKE, M.; GUSTASON, C.J. Sexuality in women with cancer. Nurs. Clin. North Am., v.42, n.4, p.507-704, 2007.

BIFFI, R.G.; MAMEDE, M.V. Suporte social na reabilitação da mulher mastectomizada: o papel do parceiro sexual. Rev. Esc. Enferm USP, v.38, n.3, p.262-9, 2004.

BRASIL. Ministério da Saúde. Resolução n 196/96. Dispõe sobre pesquisa envolvendo seres humanos. Brasília: Conselho Nacional de Saúde, 1996.

CAPRA, F. O ponto de mutação: a ciência, a sociedade e a cultura emergente. São Paulo: Cultrix, 1982.

DE MARCO, M.A. Do modelo biomédico ao modelo biopsicossocial: um projeto de educação permanente. Rev. Bras. Educ. Med., v.30, n.1, p.60-72, 2006.

DIZON, D.S. et al. The sexuality clinic in the breast center: sex as a survivorship issue. Breast Cancer Online, v.11, n.12, p.1-3, 2008.

FONTES, C.A.S.; ALVIM, N.A.T. Importância do diálogo da enfermeira com clientes oncológicos diante do impacto do diagnóstico da doença. Cienc. Cuid. Saude, v.7, n.3, p.346-54, 2008.

GIAMI, A. A saúde sexual: a medicalização da sexualidade e do bem-estar.

Rev. Bras. Sex. Hum., v.18, n.1, p.263-77, 2007.

GIDDENS, A. A transformação da intimidade: sexualidade, amor e erotismo nas sociedades modernas. São Paulo: Ed. Unesp, 1993.

HAUTAMÄKI, K. et al. Opening communication with cancer patients about sexuality-related issues. Cancer Nurs., v.30, n.5, p.399-404, 2007.

HIGGINS, A.; BARKER, P.; BEGLEYC, M. Sexuality: the challenge to espoused holistic care. Int. J. Nurs. Pract., v.12, n.6, p.345-51, 2006.

HORDERN, A.J.; STREET, A.F. Contructions of sexuality and intimacy after cancer: patient and health professional perspectives. Soc. Sci. Med., v.64, n.8, p.1704-18, 2007.

JUNQUEIRA, L.C.U. Investigação da sexualidade na experiência de enfermeiras que cuidam de pacientes com câncer de mama. s/d. Tese (Doutorado) - Faculdade de Filosofia, Ciências e Letras de Ribeirão Preto, Universidade de São Paulo, Ribeirão Preto. s/d. (em andamento)

LINDAU, S.T. et al. Communication about sexuality and intimacy in couples affected by lung cancer and their clinical-care providers. Psycho-Oncology, v.20, n.2, p.179-85, 2011.

MACIEIRA, R.C.; MALUF, M.F. Sexualidade e câncer. In: CARVALHO, V.A. et al. (Orgs.). Temas em psico-oncologia. São Paulo: Summus, 2008. p.303-15.

MINAYO, M.C.S. O desafio da pesquisa social. In: MINAYO, M.C.S.; GOMES, R.; DESLANDES, S.F. (Orgs.). Pesquisa social: teoria, método e criatividade. 27.ed. Petrópolis: Vozes, 2008. p.9-29. 
PENSON, R.T. et al. Sexuality and cancer: conversation comfort zone. Oncologist, v.5, n.4, p.336-44, 2000.

PINHEIRO, T.F.; COUTO, M.T.; SILVA, G.S.N. A abordagem à sexualidade masculina na atenção primária à saúde: possibilidades e limites. Interface -Comunic., Saude., Educ., v.15, n.38, p.845-58, 2011.

RESSEL, L.B.; GUALDA, D.M.R. A sexualidade na assistência de enfermagem: reflexões numa perspectiva cultural. Rev. Gaucha Enferm., v.25, n.3, p.323-33, 2004.

RICE, A.M. Sexuality in cancer and palliative care 2: exploring the issues. Int. J. Palliat. Nurs., v.6, n.9, p.448-53, 2000.

ROSSI, L.; SANTOS, M.A. Repercussões psicológicas do adoecimento e tratamento em mulheres acometidas pelo câncer de mama. Psicol. Cienc. Prof., v.23, n.4, p.32-41, 2003.

SANTOS, L.N. et al. Sexualidade e câncer de mama: relatos de oito mulheres afetadas. Psicol. Hosp., v.6, n.2, p.2-19, 2008.

SILVA, G.; SANTOS, M.A. Stressors in breast cancer post-treatment: a qualitative approach. Rev. Latino-am. Enferm., v.18, n.4, p.688-95, 2010.

"Será que não vai acabar nunca?": perscrutando o universo do pós-tratamento do câncer de mama. Texto Contexto Enferm., v.17, n.3, p.561-8, 2008.

STEFANELLI, M.C.; CARVALHO, E.C.; ARANTES, E.C. Comunicação e enfermagem. In: STEFANELLI, M.C.; CARVALHO, E.C. (Orgs.). A comunicação nos diferentes contextos da enfermagem. Barueri: Manole, 2005. p.1-9.

TEIXEIRA, C.A.B. et al. Comunicação interpessoal como instrumento que viabiliza a qualidade da consulta de enfermagem ginecológica. Rev. APS, v.12, n.1, p.16-28, 2009.

FINKLER, M.; CAETANO, J.C.; RAMOS, F.R.S. Análisis sobre la comunicación de la sexualidad por las enfermeras a las pacientes en el contexto asistencial del cáncer de mama. Interface - Comunic., Saude, Educ., v.17, n.44, p.89-101, jan./mar. 2013.

Fue investigado cómo se desarrolla la comunicación sobre sexualidad por enfermeras para pacientes que se sometieron a una mastectomía, en estudio cualitativo, descriptivoexploratorio. Participaron 28 enfermeras y fueron utilizadas entrevistas en profundidad. El material fue sometido al análisis de contenido temático. Se registraron variaciones en los discursos de las enfermeras, que articulan en cuatro categorías: la enfermera no comunica cuestiones de sexualidad; comunica con discurso evasivo y negación de la sexualidad en el cuidado; utiliza comunicación fragmentada, del modelo biomédico; adopta comunicación acojedora, integrada, junto a los familiares y al equipo de salud. Se evidenciaron dificultades de las enfermeras para tratar de cuestiones de sexualidad en la producción de cuidados de salud. Se espera suscitar el interés en nuevos conocimientos acerca de la interfaz entre sexualidad y cuidados en la educación de enfermería, favoreciendo la información y capacitación del equipo.

Palabras clave: Neoplasias de la mama. Sexualidad. Comunicación y enfermería. 